\title{
THE EFFECTS OF ADRENALINE, HYALURONIDASE AND AGE ON PERIBULBAR ANAESTHESIA
}

\author{
C. D. MORSMAN ${ }^{1}$ AND R. HOLDEN ${ }^{2}$ \\ Cardiff and Oxford
}

\begin{abstract}
SUMMARY
In a prospective, randomised, masked trial, 91 patients undergoing intraocular surgery received an anaesthetic mixture containing lignocaine hydrochloride $2 \%$ and bupivacaine hydrochloride $0.5 \%$. In addition group 1 had hyaluronidase (50 i.u./ml) and adrenaline (1:200,000), group 2 had hyaluronidase alone, group 3 had adrenaline alone and group 4 had neither. The groups were compared regarding the quality of operating conditions. Hyluronidase had a substantial beneficial effect though there was no significant difference related to the use of adrenaline. Anaesthesia was less effective in patients under the age of 65 years.
\end{abstract}

Although most authors recommend peribulbar infiltration for intraocular surgery under local anaesthesia, ${ }^{1-3}$ there is no consensus regarding the best anaesthetic agent. Bupivacaine $^{4}$ may be used alone or mixed with lignocaine ${ }^{1-3}$. The addition of various concentrations of hyaluronidase is usual though evidence supporting its use is conflicting ${ }^{5-8}$. Addition of adrenaline is suggested in about half the publications $^{1-4,8-10}$, though it may delay onset of effect ${ }^{11}$. The original intention of this study was to find out if the use of adrenaline conferred any clinical benefit. Hyaluronidase became unavailable in the United Kingdom in spring of 1991 and so two further groups were added though the presence or absence of hyaluronidase could not be masked as was the case with adrenaline.

\section{METHODS}

Approval from the appropriate Hospital Ethical Committees, and informed consent from the patients was obtained. While hyaluronidase was available, consecutive patients scheduled for intraocular surgery under local anaesthesia by the authors were randomly allocated to receive mixtures one or two (above), later to mixtures three or four. The anaesthetic was administered and graded by the sur-

From 'University Hospital of Wales, ${ }^{2}$ Oxford Eye Hospital.

Correspondence to: Mr. C. D. Morsman, FRCS (Ed), FCOphth, University Hospital of Wales, Heath Park, Cardiff CF4 3RH. geon. The technique was based on that described by Hamilton RC (International Symposium on Local Anaesthesia for Ophthalmic Surgery, Charing Cross Hospital, London, September 1990). No sedation was used; pulse rate and oxygen saturation were monitored with a pulse oximeter.

Following gutt. Benoxinate hydrochloride (Minims, Smith and Nephew) $4 \mathrm{ml}$ of mixture was injected transconjunctivally into the infero-temporal quadrant of the orbit to a depth of $30 \mathrm{~mm}$ from the limbus. After five minutes of digital pressure akinesia was assessed and if necessary a further $3.5 \mathrm{ml}$ injected at the medial canthus to the same depth. If after a further five minutes akinesia was still incomplete the anaesthetist gave a superior peribulbar injection or if this was considered unlikely to be effective, an inferior retrobulbar injection with the remaining $2.5 \mathrm{ml}$, the latter being recorded as a failure of the technique.

After a further period of digital pressure surgery was performed, and the quality of the operating conditions assessed as good, satisfactory or unsatisfactory according to Table I.

When 91 patients had been included the randomisation code was broken. Most (86) underwent extracapsular cataract extraction with posterior chamber intraocular lens implantation (three in combination with trabeculectomy). One had no lens implanted, two had anterior chamber lenses implanted as a secondary procedure and two underwent trabeculectomy alone. The posterior capsule or zonule was torn in five cases; two with vitreous loss. There were no other complications.

\section{RESULTS}

There was no significant difference between the results obtained by the two surgeons involved. The mean age of the patients was 73.5 years; 33 were male and 58 female with no significant difference between the four groups.

\section{Hyaluronidase}

Addition of hyaluronidase significantly increased the pro- 
Table I. Grading of anaesthesia

\begin{tabular}{|c|c|}
\hline \multicolumn{2}{|c|}{$\begin{array}{l}\text { Akinesia Globe 1. No movement } \\
\text { 2. Twitch one direction } \\
\text { 3. Twitch }>\text { one direction } \\
\text { 4. More than (3) }\end{array}$} \\
\hline Lid & $\begin{array}{l}\text { 1. No movement } \\
\text { 2. Twitch unable to overcome speculum } \\
\text { 3. Twitch, able to overcome speculum } \\
\text { 4. Blink }\end{array}$ \\
\hline Compliance & $\begin{array}{l}\text { 1. PC concave backward after I/A } \\
\text { 2. PC in pupil (or AC deep in trabeculectomy) } \\
\text { 3. AC shallow } \\
\text { 4. Difficulty maintaining AC }\end{array}$ \\
\hline Pain & $\begin{array}{l}\text { 1. None } \\
\text { 2. Subconj. injection only felt } \\
\text { 3. Discomfort throughout } \\
\text { 4. Pain throughout }\end{array}$ \\
\hline
\end{tabular}

Good $=$ groups 1 or 2 in all categories

Satisfactory = group 3 in any category

Unsatisfactory = group 4 in any category

portion attaining 'good' anaesthesia from $33 \%$ to $69 \%$ $(\mathrm{p}<0.05)$. The need for a third injection dropped from $90 \%$ to $30 \%$ with addition of hyaluronidase. Further analysis was therefore restricted to the 61 patients who received hyaluronidase.

\section{Adrenaline}

There was no significant difference between the group that had adrenaline in the anaesthetic (62\% 'good' anaesthesia and $69 \%$ requiring fewer than three injections) and the one that did not $(75 \%$ 'good' anaesthesia and $72 \%$ requiring fewer than three injections (Table III).

\section{Age}

An unexpected finding was the reduced effectiveness of local anaesthesia in patients under the age of 65 years. Only $25 \%$ attained good operating conditions compared to $80 \%$ of the over 65 -year-old patients $(\mathrm{p}<0.0006)$. A much higher proportion of patients required a third injection in the younger age group ( $50 \%$ vs $24 \%$ ), though this failed to reach statistical significance (Table IV).

\section{DISCUSSION}

The most common anaesthetic agents used for peribulbar

Table II. Effect of hyaluronidase

\begin{tabular}{lcccc}
\hline Quality & With & Without & p & CI \\
\hline Good & 42 & 10 & $<0.05^{*}$ & 15 to $56 \%$ \\
Satisfactory & 19 & 20 & & \\
\hline $\begin{array}{l}\text { Injections } \\
1 \text { or 2 }\end{array}$ & 43 & 3 & & \\
3 & 18 & 27 & $<0.0001 \S$ & 45 to $76 \%$ \\
\hline
\end{tabular}

*Yates' continuity correction to Chi squared test

$\S$ Fisher exact test

CI $95 \%$ confidence interval anaesthesia are lignocaine, bupivacaine, or a mixture of the two ${ }^{1-4,8-11}$. Lignocaine provides a rapid onset of anaesthesia and akinesia, bupivacaine gives prolonged postoperative pain relief $^{12}$. Various adjuncts include hyaluronidase, adrenaline and bicarbonate ${ }^{11}$ though the interaction between these chemicals is incompletely understood. Zahl et al. ${ }^{11}$ found bicarbonate helpful and adrenaline deleterious, though they concentrated on rapidity of onset which is surely less important than the quality of the anaesthetic, particularly when a minimum of 20 minutes ocular compression is recommended by some authors ${ }^{2-4}$. House et al. on the other hand found both adrenaline and hyaluronidase vital for satisfactory anaesthesia, though they used a ten-fold smaller dose of hyaluronidase and confounded the analysis with numerous small groups ${ }^{8}$.

With retrobulbar anaesthesia, hyaluronidase has been found to be beneficial whether adrenaline was used or not $^{6,7}$, though in a smaller study there was a possible adverse effect ${ }^{5}$. In our hands peribulbar anaesthesia without hyaluronidase appeared to be unsatisfactory (though this part of the trial was not masked). Hyaluronidase' is said to break down the fibrous septa of the orbit, facilitating diffusion of the anaesthetic agent. The injectate has to spread much farther around the orbit for the peribulbar technique to be successful so hyaluronidase is theoretically more helpful with this technique than with the retrobulbar approach. A larger volume of anaesthetic agent is used in the peribulbar approach, and if this remains localised behind the globe, intraorbital pressure may be raised contributing to poor operating conditions.

The rationale for using adrenaline is generally not stated; duration of effect should be adequate for intraocular surgery if bupivacaine is used, bleeding from a scleral incision can be controlled with cautery, and pupil dilatation maintained by adrenaline in the irrigating solution. Systemic absorption of the anaesthetic agents may be reduced but bupivacaine in particular has a high affinity for the tissues ${ }^{13}$. The dose of anaesthetic agent used for peribulbar anaesthesia is below the toxic level ${ }^{13}$ and the risk has to be balanced against the systemic effects of adrenaline, such as cardiac arrhythmia. Plasma levels of exogenous adrenaline have been shown to rise threefold from ocular anaesthesia, though no significant pressor response occurred ${ }^{14}$. Toxic reactions are most likely if intravascular injection occurs, and in this situation adrena-

Table III. Effect of adrenaline

\begin{tabular}{lcccc}
\hline Quality & With & Without & $p$ & CI \\
\hline Good & 18 & 24 & NS & -36 to $10 \%$ \\
Satisfactory & 11 & 8 & & \\
\hline $\begin{array}{l}\text { Injections } \\
1 \text { or 2 }\end{array}$ & 20 & 23 & & \\
3 & 9 & 9 & NS & -26 to $20 \%$ \\
\hline
\end{tabular}

NS no significant difference

Yates' continuity correction to Chi squared test 
Table IV. Age

\begin{tabular}{lcccc}
\hline Quality & $<65$ & $\geqslant 65$ & $\mathrm{p}$ & $\mathrm{CI}$ \\
\hline Good & 3 & 39 & & \\
Satisfactory & 9 & 10 & & 28 to $82 \%$ \\
\hline $\begin{array}{l}\text { Injections } \\
1 \text { or 2 }\end{array}$ & 6 & 37 & & \\
3 & 6 & 12 & NS & \\
\hline
\end{tabular}

Fisher exact test

NS no significant difference

line is more hazardous than the local anaesthetic ${ }^{15}$. We found no benefit from the use of adrenaline to justify this risk.

It has been suggested that commercially available anaesthetics containing adrenaline are less effective because of lower $\mathrm{pH}^{11}$ and there was a trend for our results to support this though statistical significance was not reached.

There is no obvious reason why age should be important. It may be that the fibrous septa of the orbit are thicker in younger patients. If this is the case increasing the concentration of hyaluronidase may help, though we used a higher concentration than is often the case.

This study confirms the generally favourable operating conditions provided by peribulbar anaesthesia. The use of hyaluronidase is encouraged pending a large, fully masked trial, though adrenaline appears to offer no benefit. In patients under the age of 65 the poorer response should be considered when deciding whether to operate under local or general anaesthesia.

We would like to thank S. Kent SRN, D. Grubert SRN and A. Ablett SEN for assistance with the randomisation and masking. Mrs C. M. Lane and Prof A. J. Bron kindly allowed their patients to be recruited to the study.
Key words: Adrenaline; Age; Bupivacaine; Hyaluronidase; Lignocaine; Peribulbar anaesthesia.

\section{REFERENCES}

1. Weis JL and Deichman CB: A comparison of retrobulbar and periocular anaesthesia for cataract surgery. Arch Ophthalmol 1989, 107: 96-8.

2. Whitsett JC, Balyeat HD, McClure B: Comparison of oneinjection-site peribulbar anaesthesia and retrobulbar anaesthesia. J Cataract Refract Surg 1990, 16: 243-45.

3. Hamilton RC, Gimbel HV, Strunin L: Regional anaesthesia for 12,000 cataract extraction and intraocular lens implantation procedures. Can J Anaesth 1988, 35: 615-23.

4. Wang HS: Peribulbar anaesthesia for ophthalmic procedures. J Cataract Refract Surg 1988, 14: 441-3.

5. Mindel JS: Value of hyaluronidase in ocular surgical akinesia. Am J Ophthalmol 1978, 85: 643-6.

6. Nicol JMV, Treuren B, Acharya PA, et al.: Retrobulbar anaesthesia: the role of hyaluronidase. Anaesth Analg 1986, 65: $1324-8$.

7. Thomson I: Addition of hyaluronidase to lignocaine with adrenaline for retrobulbar anaesthesia in the surgery of senile cataract. Br J Ophthalmol 1988, 72: 700-2.

8. House PH, Hollands RH, Schulzer M: Choice of anaesthetic agents for peribulbar anaesthesia. J Cataract Refract Surg 1991, 17: 80-3.

9. Fry RA and Henderson J: Local anaesthesia for eye surgery. Anaesthesia 1989, 45: 14-17.

10. Johnson DE and Gills JP: Advanced ophthalmic anaesthesia. In Spaeth G, Katz LJ (eds): Current therapy in ophthalmic surgery. BC Becker, Toronto, 1989, 1-5.

11. Zahl K, Jordan A, McGroarty J, et al.: Peribulbar anaesthesia. Effect of bicarbonate on mixtures of lignocaine, bupivacaine, and hyaluronidase with or without epinephrine. Ophthalmology 1991, 98: 239-42.

12. $\mathrm{Oji} \mathrm{E}$ and $\mathrm{Oji} \mathrm{A}$ : Bupivacaine and lignocaine for ophthalmic surgery. Br J Ophthalmol 1987, 71: 66-8.

13. Calvey TN, Williams NE: Principles and practice of pharmacology for anaesthetists. 2nd ed. Oxford, Blackwell 1991: 228-55.

14. Donlon JV, Moss J: Plasma catecholamine levels during local anaesthesia for cataract operations. Anaesthesiology 1979, 51: 471-3.

15. Reynolds F: Adverse effects of local anaesthetics. Br J Anaesth 1987, 59: 78-95. 